\title{
Optimal design of through-truss steel bridges
}

\author{
C. Maraveas ${ }^{1,2}$, A. Papagiannakis ${ }^{1}, \mathrm{~K}$. Miamis ${ }^{1} \&$ K. Tasiouli ${ }^{1}$ \\ ${ }^{I}$ C. MARAVEAS PARTNERSHIP, Consulting Engineers, Greece \\ ${ }^{2}$ School of Mechanical, Aerospace and Civil Engineering, \\ University of Manchester, UK.
}

\begin{abstract}
Structural optimisation is a topic which gathers the interest of many research teams and engineers. Its purpose is to minimise an objective function, such as the weight of a structure, subjected to certain constraints (e.g. compliance of structural members with code requirements). In this paper, optimal design (in terms of shape and sizing) of through-truss steel bridges is performed. Several cases of simply supported bridges with different spans $(40 \mathrm{~m}, 50 \mathrm{~m}$ and $60 \mathrm{~m})$ and varying width, corresponding to one or two traffic lanes, were examined. For the aforementioned bridges, the effect of three deck types (reinforced concrete deck, fiber reinforced polymer deck and steel deck) on the weight of the truss and the total weight was investigated. Least-weight shape and sizing optimal design was executed, with the height of the truss and the cross-section areas of its members constituting the design variables of the problem. The structural analysis and design were conducted in accordance with the specifications of the Eurocodes. The influence of both the height-to-span ratio and the deck type on the weight of the truss, the total weight and the cost is discussed based on the results obtained from the optimisation procedure.

Keywords: optimal design, steel bridges, frp deck, concrete deck, steel deck, cost analysis of bridges.
\end{abstract}

\section{Introduction}

Optimal design of bridges is an integral part of structural optimisation. Significant work on this topic has been conducted in the past few decades [1-3]. Most commonly, the optimum solution involves minimising the weight of the structure and, consequently, the erection cost. This study focuses on shape and sizing optimal design of simply supported through-truss steel bridges. Different 
configurations, spans and deck types were investigated. The purpose is to determine the optimum height-to-span ratio for this bridge system and study the influence of the deck type on the weight of the truss and that of the complete structure. Moreover, cost data for the studied bridges are presented in order to highlight the most efficient, in financial terms, solution.

\section{Bridge model details}

\subsection{Layout}

The simply supported, through-truss steel bridges presented in this paper follow a Pratt truss configuration, which results in tension of the diagonal members under the vertical loading. Three different spans were investigated. A schematic representation of a bridge with one and two traffic lanes is given in figs 1 and 2 respectively. Typical cross-sections of the bridges, along with their geometric characteristics, are depicted in fig. 3. It should be noted that a pavement exists on one side of the road and a vehicle parapet on the other. The span between the vertical members of the truss is $2.5 \mathrm{~m}$ for the $40 \mathrm{~m}$ and $50 \mathrm{~m}$ spans and $3 \mathrm{~m}$ for the $60 \mathrm{~m}$ span. Moreover, the top chord is formed from straight members, connected on a parabolic curve. The height of the first vertical member of the truss is fixed at $2 \mathrm{~m}$, while the height of the truss at midspan constitutes the shape's optimisation design variable, as described in section 2.4. The span of the vertical truss members was selected to restrain the angle of the diagonals between $35^{\circ}$ and $65^{\circ}$ approximately and reduce the buckling length of the compressed members.

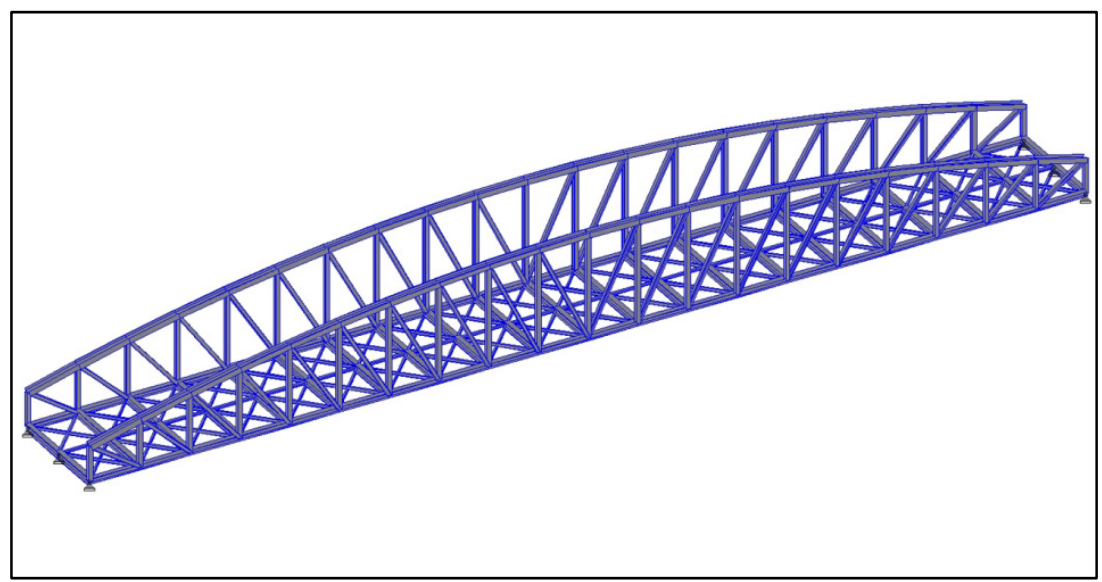

Figure 1: Model of the truss bridge with one traffic lane. 


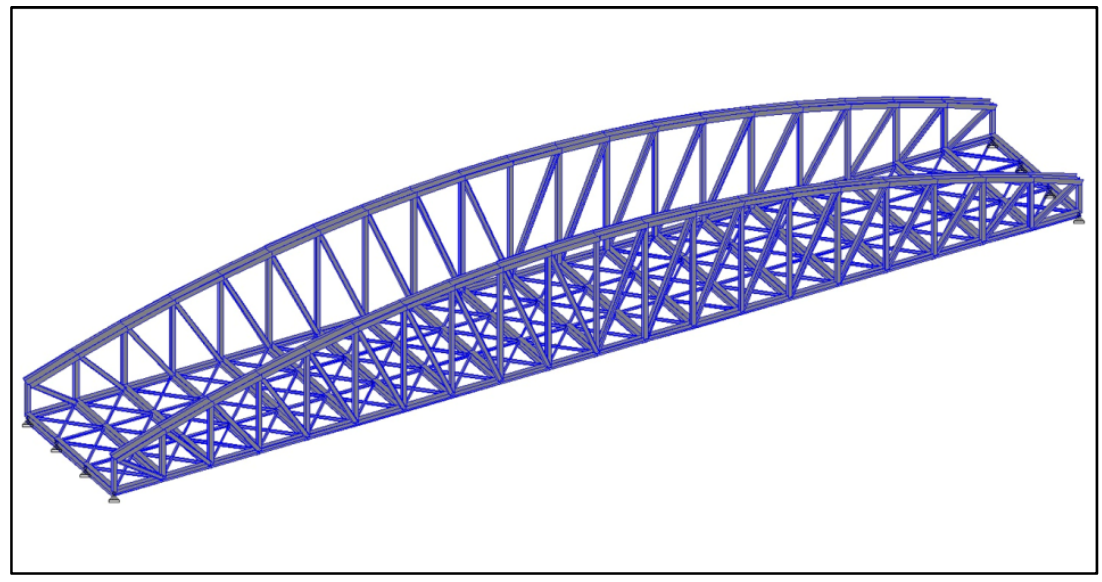

Figure 2: Model of the truss bridge with two traffic lanes.

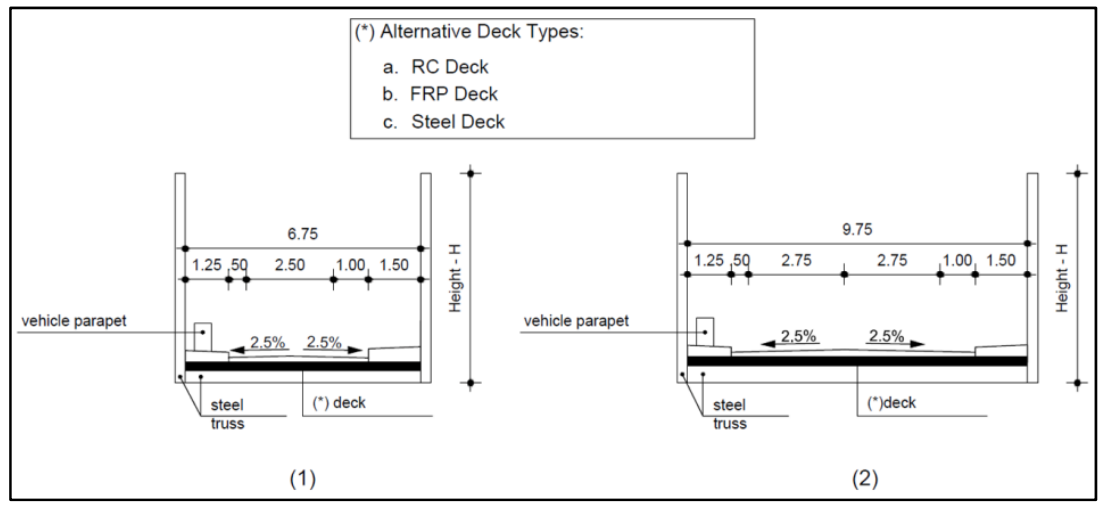

Figure 3: Bridge cross-sections for one (1) and two (2) traffic lanes.

It should be highlighted that top lateral bracing is not included in the studied bridge configurations. Such structures are typically referred to as "open-top" or "half-through-truss" bridges [4]. In such a system, a moment connection between the vertical members and the cross girders is necessary, in order to create a semiframe capable of restraining the out-of-plane buckling of the compressed top chord members.

During the optimisation process, a different cross-section was assigned to the top chord members, bottom chord members, diagonal members, vertical members, cross girders, stringers and bottom lateral bracing members. 


\subsection{Deck}

Three different deck types were considered in the present study. The first alternative studied was a reinforced concrete (RC) deck, with a $5 \mathrm{KN} / \mathrm{m}^{2}$ selfweight, the second a fibre reinforced polymer (FRP) deck, weighing $1.5 \mathrm{KN} / \mathrm{m}^{2}$ and the third a steel deck with a weight of $2.5 \mathrm{KN} / \mathrm{m}^{2}$. For the cost analysis of the bridge, rates from suppliers and agents were used, including the cost of manufacturing, delivery, installation and overlay.

\subsection{Loads and design}

The traffic loads specified in EN1991-2 [5] were applied to the studied structures. Wind action per EN1991-1-4 [6] was also taken into account. All relevant analyses were performed by the commercial software STAAD.Pro V8i [7], which implements the Finite Element Method (FEM). The design of the steel members, which complies with the requirements of EN1993-1-1 [8] and EN1993-2 [9] for steel bridges, was also carried out by the same software [7]. The selected quality for steel was S355.

It should be noted that the structures examined were open-top through-truss steel bridges. The necessary checks specified in EN1993-2 [9] regarding buckling of the top chord's compressed members are not performed by STAAD.Pro V8i [7]. Consequently, an additional routine was implemented in Matlab to cover this specific requirement of EN1993-2 [9]. This routine calculates the top chord resistance according to the geometry, configuration of the semi-frame, member sections etc. and performs the necessary adequacy check against the design axial force.

\subsection{Optimisation process}

The objective function of the optimisation problem was the weight of the truss, with the Eurocode's design requirements being the constraints. The target of the optimisation process was to minimise the objective function. Shape optimisation of the truss was conducted by selecting its height at midspan as the design variable. The cross-sectional areas of the members constituted the sizing optimisation design variables. European standard hot-rolled sections were selected for the steel members, according to the following pattern: a) top chord members - HEA or HEB, b) bottom chord members - HEA, c) diagonal members - HEA, d) vertical members - HEB, e) cross girders - HEB, f) stringers - HEA, g) bottom lateral bracing members - IPE. For each cycle of the shape optimisation process, iterations for selecting the member sections were performed to obtain the least weight of the truss, while the structure conformed to all design requirements. The flow chart of the process is displayed in fig. 4. 


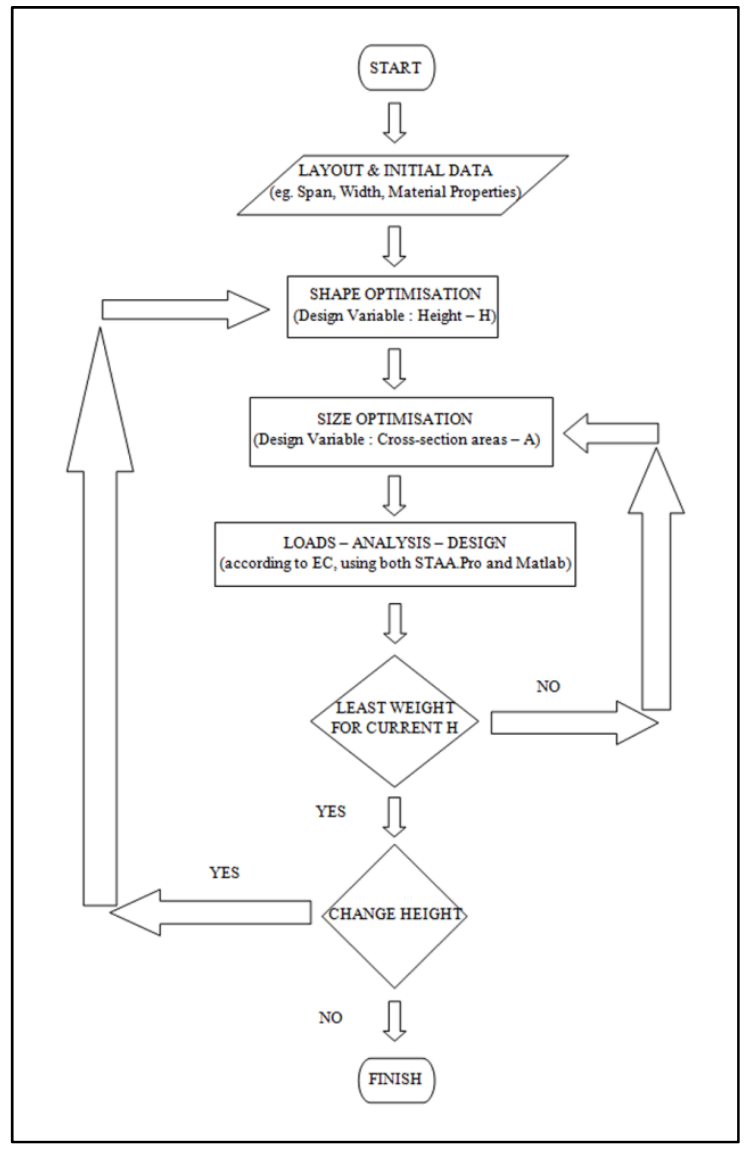

Figure 4: Flow chart of the optimisation procedure.

\section{Results and discussion}

The results of the optimisation process for the $40 \mathrm{~m}$ bridge refer to the truss weight (fig. 5) and the total weight (fig. 6) for two (continuous lines) as well as one (dotted lines) traffic lanes. Each point in the diagrams is obtained from the sizing optimisation process for the specific height depicted. Similarly, results for the span of $50 \mathrm{~m}$ are presented in fig. 7 and fig. 8, while the relevant output for the case of $\mathrm{L}=60 \mathrm{~m}$ is displayed in fig. 9 and fig. 10 . 


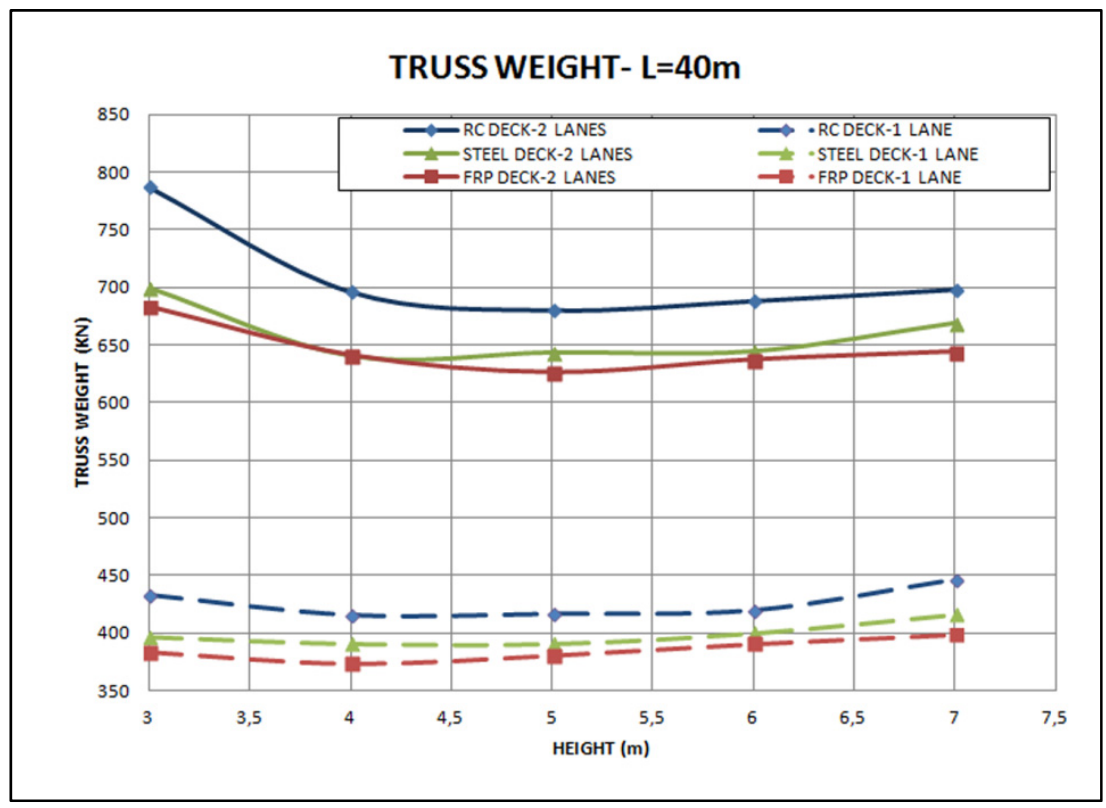

Figure 5: Steel truss weight with respect to $\mathrm{H}-40 \mathrm{~m}$ span.

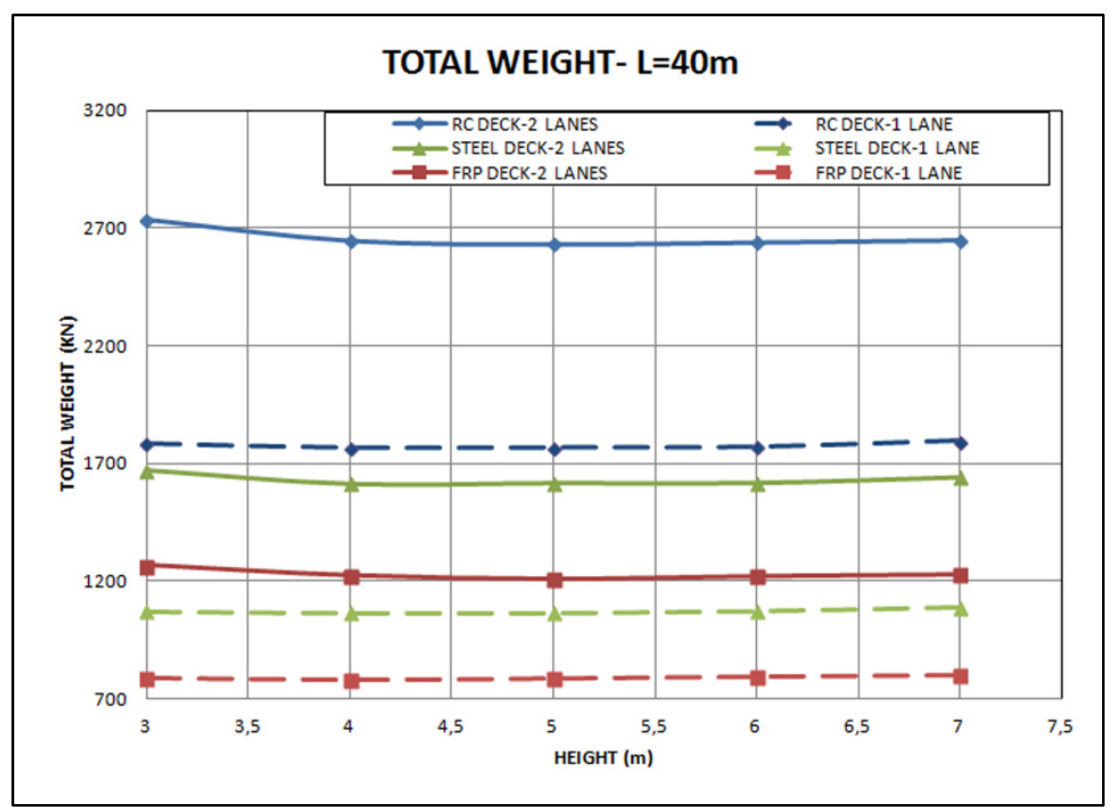

Figure 6: Bridge total weight with respect to $\mathrm{H}-40 \mathrm{~m}$ span 


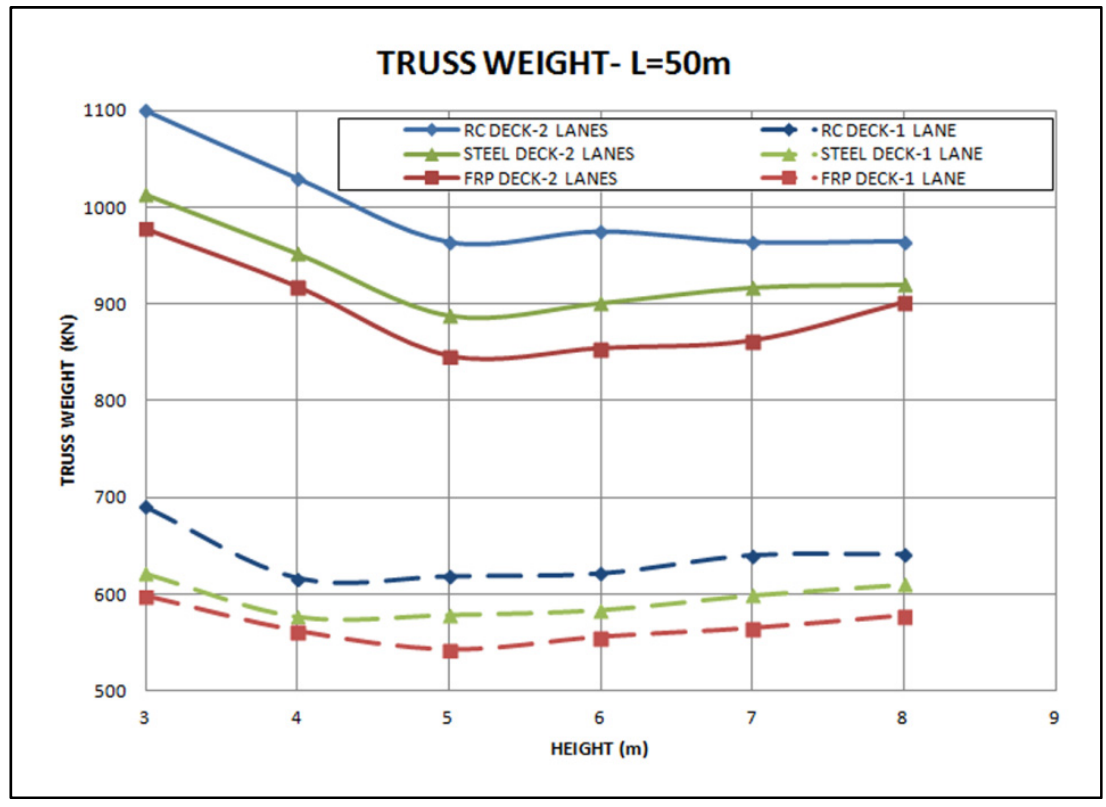

Figure 7: Steel truss weight with respect to $\mathrm{H}-50 \mathrm{~m}$ span.

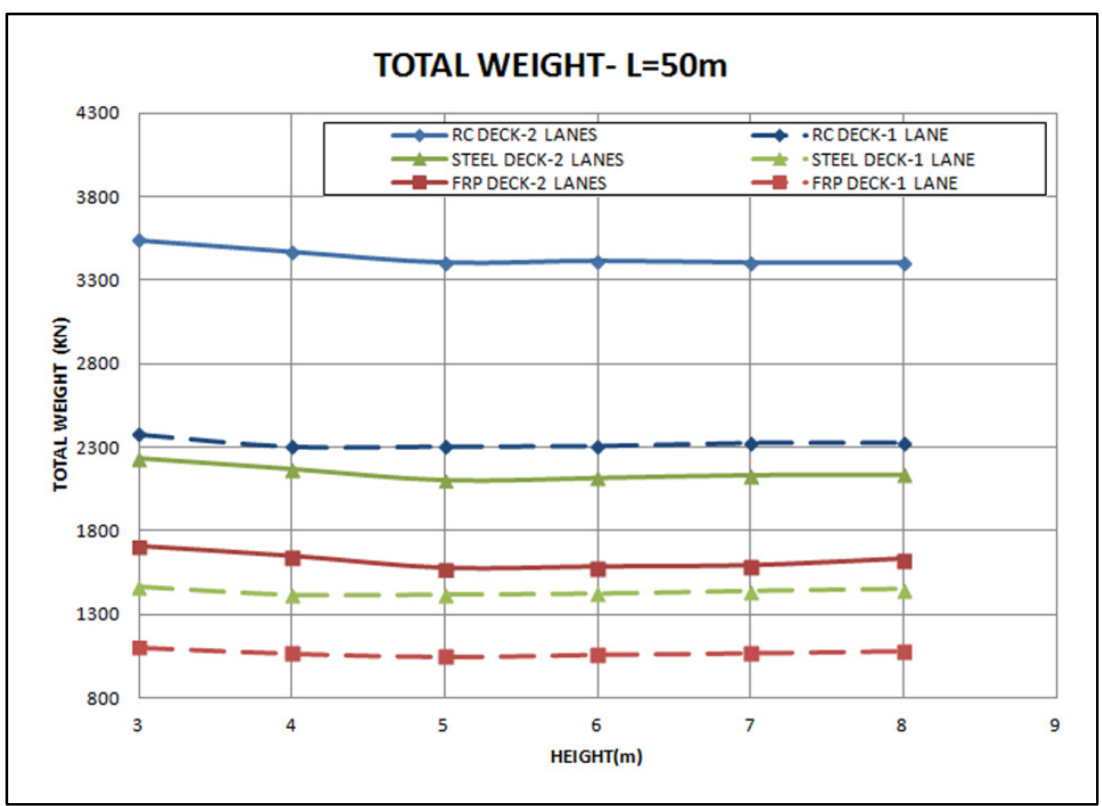

Figure 8: Bridge total weight with respect to $\mathrm{H}-50 \mathrm{~m}$ span. 


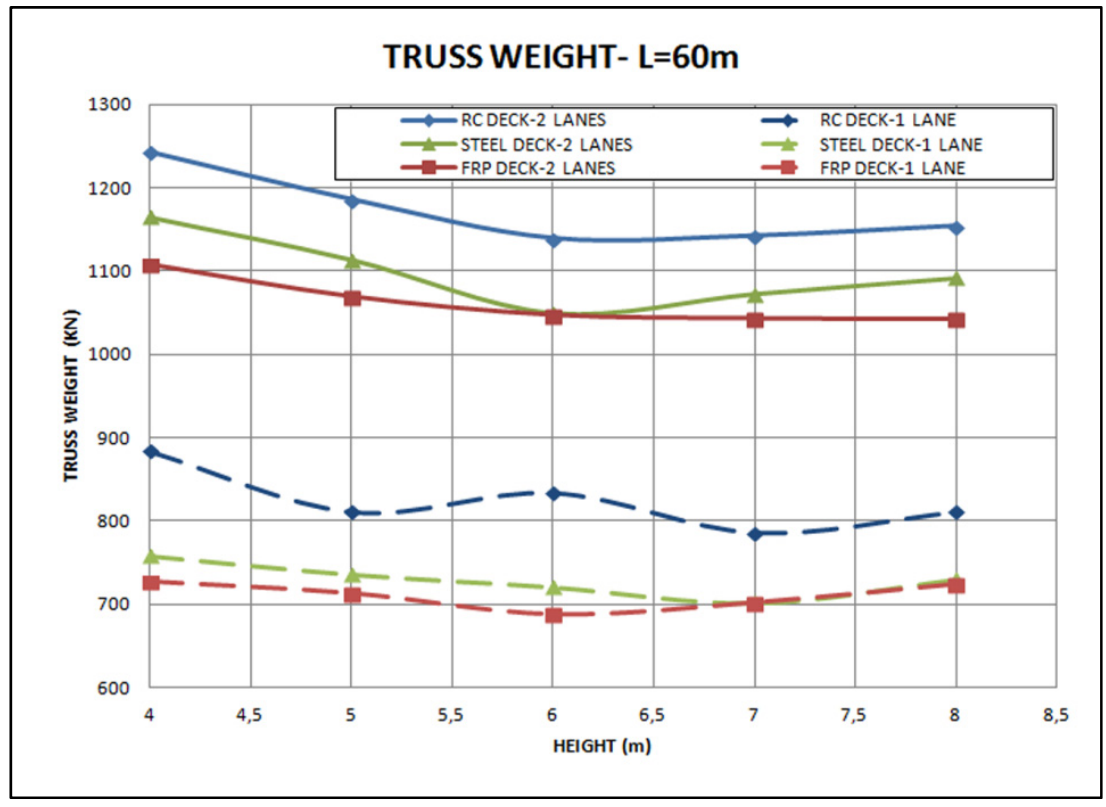

Figure 9: Steel truss weight with respect to $\mathrm{H}-60 \mathrm{~m}$ span.

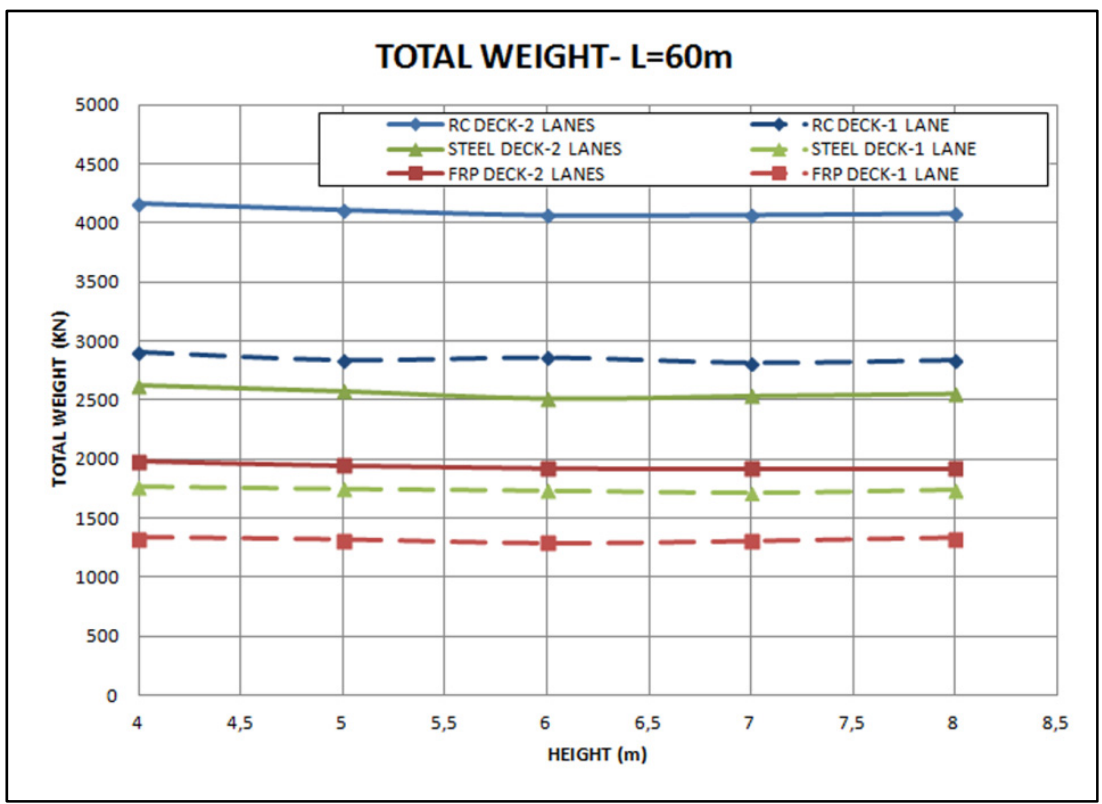

Figure 10: Bridge total weight with respect to $\mathrm{H}-60 \mathrm{~m}$ span. 
In table 1, the optimum (least) weight for each deck type is presented. The values for all studied bridges are normalised with respect to the RC deck case.

Table 1: Optimum weight for the studied bridges normalised to the $\mathrm{RC}$ deck case.

\begin{tabular}{|c|c|c|c|c|}
\hline $\mathrm{L}=40 \mathrm{~m}$ & \multicolumn{2}{|c|}{2 Traffic lanes } & \multicolumn{2}{|c|}{1 Traffic lane } \\
\hline Deck & $\begin{array}{l}\text { Normalised } \\
\text { truss weight }\end{array}$ & $\begin{array}{l}\text { Normalised } \\
\text { total weight }\end{array}$ & $\begin{array}{l}\text { Normalised } \\
\text { truss weight }\end{array}$ & $\begin{array}{l}\text { Normalised } \\
\text { total weight }\end{array}$ \\
\hline $\mathrm{RC}$ & 1.00 & 1.00 & 1.00 & 1.00 \\
\hline FRP & 0.92 & 0.46 & 0.90 & 0.44 \\
\hline Steel & 0.94 & 0.61 & 0.94 & 0.60 \\
\hline $\mathrm{L}=50 \mathrm{~m}$ & \multicolumn{2}{|c|}{2 Traffic lanes } & \multicolumn{2}{|c|}{1 Traffic lane } \\
\hline Deck & $\begin{array}{l}\text { Normalised } \\
\text { truss weight }\end{array}$ & $\begin{array}{l}\text { Normalised } \\
\text { total weight }\end{array}$ & $\begin{array}{l}\text { Normalised } \\
\text { truss weight }\end{array}$ & $\begin{array}{l}\text { Normalised } \\
\text { total weight }\end{array}$ \\
\hline $\mathrm{RC}$ & 1.00 & 1.00 & 1.00 & 1.00 \\
\hline FRP & 0.88 & 0.46 & 0.88 & 0.46 \\
\hline Steel & 0.92 & 0.62 & 0.94 & 0.62 \\
\hline $\mathrm{L}=60 \mathrm{~m}$ & \multicolumn{2}{|c|}{2 Traffic lanes } & \multicolumn{2}{|c|}{1 Traffic lane } \\
\hline Deck & $\begin{array}{l}\text { Normalised } \\
\text { truss weight }\end{array}$ & $\begin{array}{l}\text { Normalised } \\
\text { total weight }\end{array}$ & $\begin{array}{l}\text { Normalised } \\
\text { truss weight }\end{array}$ & $\begin{array}{l}\text { Normalised } \\
\text { total weight }\end{array}$ \\
\hline $\mathrm{RC}$ & 1.00 & 1.00 & 1.00 & 1.00 \\
\hline FRP & 0.92 & 0.47 & 0.88 & 0.46 \\
\hline Steel & 0.93 & 0.62 & 0.89 & 0.61 \\
\hline
\end{tabular}

Table 1 provides useful information regarding the effect of the deck type on the weight of the structural system. The decrease in truss weight is minor $(8 \%$ to $12 \%$ approximately) when an FRP deck is used instead of a RC one. In a similar way, the weight reduction for using a steel deck ranges between $6 \%$ and $11 \%$. On the contrary, the deck type heavily influences the total weight of the structure. In the case of an FRP deck, a 55\% reduction of the total weight was observed. For a steel deck, the decrease was lower, but still considerable (approximately 40\%). The obtained optimum height-to-span ratio is presented in table 2.

Table 2: Optimum height-to-span (H/L) ratio for the studied cases.

\begin{tabular}{|c|c|c|c|c|c|c|}
\hline & \multicolumn{2}{|c|}{$\mathrm{L}=40 \mathrm{~m}$} & \multicolumn{2}{c|}{$\mathrm{L}=50 \mathrm{~m}$} & \multicolumn{2}{c|}{$\mathrm{L}=60 \mathrm{~m}$} \\
\hline Deck & 2 Lanes & 1 Lane & 2 Lanes & 1 Lane & 2 Lanes & 1 Lane \\
\hline RC & 0.125 & 0.100 & 0.100 & 0.080 & 0.100 & 0.120 \\
\hline FRP & 0.125 & 0.100 & 0.100 & 0.100 & 0.130 & 0.100 \\
\hline Steel & 0.100 & 0.100 & 0.100 & 0.080 & 0.100 & 0.120 \\
\hline
\end{tabular}

From this table, it can be concluded that a height-to-span ratio between $1 / 7$ and $1 / 10$ is the optimum for a bridge with two traffic lanes, while a value within the range of $1 / 8$ and $1 / 12$ should be selected when one traffic lane is considered. 
Additionally, shape optimisation reduces the weight of the truss by $7 \%$ to $15 \%$ for the studied height ranges.

Moreover, a cost analysis for the examined bridges was conducted. In table 3, the prices of the materials that were taken into account are presented. It should be noted that for the FRP deck only, the price includes the cost of the overlay. Estimated cost values for the bridges are displayed in table 4. For comparison purposes, all values were also normalised with respect to the RC deck case. It should be mentioned that all values include the agency's initial costs for the deck and the steel truss, namely the cost of manufacturing, delivery, installation, overlay etc. and not future or maintenance costs as in the case of a life cycle cost analysis [10].

Table 3: Material prices provided by suppliers.

\begin{tabular}{|c|c|c|c|c|}
\hline Steel truss & RC Deck & FRP Desk & Steel Deck & Overlay \\
\hline $2 € / \mathrm{Kg}$ & $200 € / \mathrm{m}^{3}$ & $750 € / \mathrm{m}^{2}$ & $2 € / \mathrm{Kg}$ & $25 € / \mathrm{m}^{2}$ \\
\hline
\end{tabular}

Table 4: Estimated absolute costs $(€)$ for the bridges and normalized values with respect to the $\mathrm{RC}$ deck case.

\begin{tabular}{|c|c|c|c|c|c|c|}
\hline $\mathrm{L}=40 \mathrm{~m}$ & \multicolumn{6}{|c|}{2 Traffic lanes } \\
\hline Deck & \multicolumn{2}{|c|}{ Steel truss } & \multicolumn{2}{|c|}{ Deck and Overlay } & \multicolumn{2}{|c|}{ Total cost } \\
\hline $\mathrm{RC}$ & 136000 & 1.00 & 25500 & 1.00 & 161500 & 1.00 \\
\hline FRP & 125000 & 0.92 & 292500 & 11.50 & 417500 & 2.60 \\
\hline Steel & 128000 & 0.94 & 205000 & 8.10 & 333000 & 2.07 \\
\hline & \multicolumn{6}{|c|}{1 Traffic lane } \\
\hline Deck & \multicolumn{2}{|c|}{ Steel truss } & \multicolumn{2}{|c|}{ Deck and Overlay } & \multicolumn{2}{|c|}{ Total cost } \\
\hline $\mathrm{RC}$ & 83000 & 1.00 & 17500 & 1.00 & 100500 & 1.00 \\
\hline FRP & 75000 & 0.90 & 202500 & 11.50 & 277500 & 2.76 \\
\hline Steel & 78000 & 0.94 & 142000 & 8.10 & 220000 & 2.20 \\
\hline $\mathrm{L}=50 \mathrm{~m}$ & \multicolumn{6}{|c|}{2 Traffic lanes } \\
\hline Deck & \multicolumn{2}{|c|}{$\begin{array}{l}\text { Steel truss } \\
\end{array}$} & \multicolumn{2}{|c|}{ Deck and Overlay } & \multicolumn{2}{|c|}{ Total cost } \\
\hline $\mathrm{RC}$ & 193000 & 1.00 & 31500 & 1.00 & 224500 & 1.00 \\
\hline FRP & 169000 & 0.88 & 365500 & 11.50 & 534500 & 2.38 \\
\hline Steel & 178000 & 0.92 & 256000 & 8.10 & 434000 & 1.93 \\
\hline & \multicolumn{6}{|c|}{1 Traffic lane } \\
\hline Deck & \multicolumn{2}{|c|}{ Steel truss } & \multicolumn{2}{|c|}{ Deck and Overlay } & \multicolumn{2}{|c|}{ Total cost } \\
\hline $\mathrm{RC}$ & 123000 & 1.00 & 22000 & 1.00 & 145000 & 1.00 \\
\hline FRP & 109000 & 0.89 & 253000 & 11.50 & 362000 & 2.50 \\
\hline Steel & 115000 & 0.93 & 177000 & 8.10 & 292000 & 2.00 \\
\hline $\mathrm{L}=60 \mathrm{~m}$ & \multicolumn{6}{|c|}{2 Traffic lanes } \\
\hline Deck & \multicolumn{2}{|c|}{ Steel truss } & \multicolumn{2}{|c|}{ Deck and Overlay } & \multicolumn{2}{|c|}{ Total cost } \\
\hline $\mathrm{RC}$ & 228000 & 1.00 & 38000 & 1.00 & 266000 & 1.00 \\
\hline FRP & 209000 & 0.91 & 439000 & 11.50 & 648000 & 2.45 \\
\hline Steel & 210000 & 0.92 & 307000 & 8.10 & 517000 & 1.95 \\
\hline & \multicolumn{6}{|c|}{1 Traffic lane } \\
\hline Deck & \multicolumn{2}{|c|}{ Steel truss } & \multicolumn{2}{|c|}{ Deck and Overlay } & \multicolumn{2}{|c|}{ Total cost } \\
\hline $\mathrm{RC}$ & 157000 & 1.00 & 26500 & 1.00 & 183500 & 1.00 \\
\hline FRP & 138000 & 0.88 & 304000 & 11.5 & 442000 & 2.40 \\
\hline Steel & 140000 & 0.89 & 213000 & 8.10 & 353000 & 1.92 \\
\hline
\end{tabular}


From table 4 it is observed that a solution other than the RC deck, leads to a marginal decrease in the cost of the steel truss (10\% for the FRP and $8 \%$ for steel deck, respectively). This is attributed to the bridge's lighter superstructure, due to the reduced self-weight of the FRP or steel deck. Nonetheless, the cost of the deck and the required overlay is substantially higher for the cases of the FRP (approximately 11.5 times higher) or steel deck (approximately 8 times higher). In terms of total erection cost, bridges with FRP decks are approximately 2.5 times more expensive than those with an RC deck, while steel deck bridges cost approximately $105 \%$ more. It should be emphasised that these values are influenced by the rates of the suppliers. A life-cycle cost analysis should be performed in order to compare the aforementioned solutions throughout the working life of the bridge. Comparing the FRP and steel deck alternatives, the cost of the first appears to be higher. However, the FRP deck has a high corrosion resistance compared with the steel deck, and, therefore, requires a reduced maintenance cost.

The RC deck solution is the most efficient from a financial point of view. Nevertheless, this alternative leads to an increased dead load, which might be critical for the foundation, as it is expected to cause greater settlements or exceed soil resistance. Therefore, for a soil profile with poor geotechnical characteristics, this alternative will most probably not lead to a practical / costefficient solution for the foundation. If this is the case, FRP / steel decks are preferable. On the other hand, for favourable foundation conditions (e.g. stiff soil or rock), the option of an $\mathrm{RC}$ deck is the most suitable from a design and financial perspective. Consequently, the selection of the deck system for a steel through-truss bridge should not be based solely on the erection cost of the superstructure.

\section{Conclusions}

Shape and sizing optimal design for open-top through-truss steel bridges was performed in this paper. Three different spans $(40 \mathrm{~m}, 50 \mathrm{~m}$ and $60 \mathrm{~m})$ were examined. For each span, the sub-cases of bridges with one and two traffic lanes were investigated. In addition, three different deck types were taken into consideration (RC, FRP or steel deck). The analysis and design were performed according to the current Eurocodes. Based on the conducted study, the following conclusions can be drawn:

- The optimum height-to-span ratio for through-truss steel bridges of medium span falls within the range of $1 / 7$ and $1 / 10$ for two traffic lanes and between $1 / 8$ and $1 / 12$ for a single lane, irrespective of deck type.

- For a given deck type, the proposed optimisation process can result in reducing the truss weight by up to $15 \%$ (two traffic lanes) or by up to $10 \%$ (one traffic lane).

- The height of the truss (when it ranges from $3 \mathrm{~m}$ to $8 \mathrm{~m}$ ) has a minor influence (less than 5\%) on the total weight of the super-structure. The latter is determined from the selection of the deck type. 
- The RC deck is the most cost-efficient solution when the total weight of the superstructure is not a restraining factor in the design of the bridge.

- When reducing the weight is a crucial factor for the design of the superstructure (due to crossing of heavier vehicles) and its foundation (e.g. poor foundation conditions), a lightweight deck (FRP or steel) is the most appropriate solution.

\section{References}

[1] Schelling, D. R., Fu, C. C., Hsu, Y. T., A cost optimized steel bridge girder design for AASHTO - WSD and LFD, Journal of Advanced Transportation, Volume 23, Issue 1, pp. 67-88, 1989.

[2] Memari, A. M., West, H. H., Cavalier, T. M., Optimization of continuous steel plate girder bridges, Springer Verlag, Structural Optimization, Volume 3, Issue 4, pp. 231-239, 1991.

[3] Pandia Raj, R., Kalyanaraman, V., GA based Optimal Design of Steel Truss Bridge, Proc. of the 6th World Congress on Structural and Multidisciplinary Optimization (WCSMO6), Rio de Janeiro, Brazil, 2005.

[4] US Department of Transportation Federal Highway Administration, Steel Bridge Design Handbook, Selecting the Right Bridge Type, Publication No. FHWA-IF-12-052 - Vol. 5, 2012.

[5] European Committee for Standardization. Eurocode 1: Actions on structures - Part 2: Traffic loads on bridges, European Standard EN 19912. Brussels, Belgium, 2004.

[6] European Committee for Standardization. Eurocode 1: Actions on structures - General Actions - Part 1-4: Wind actions, European Standard EN 1991-1-4. Brussels, Belgium, 2005.

[7] Bentley Systems, Incorporated. (2007). STAAD.Pro V8i Structural Analysis and Design Software, U.S.A.

[8] European Committee for Standardization. Eurocode 3: Design of steel structures - Part 1-1: General rules and rules for buildings, European Standard EN 1993-1-1. Brussels, Belgium, 2005.

[9] European Committee for Standardization. Eurocode 3: Design of steel structures - Part 2: Steel Bridges, European Standard EN 1993-2. Brussels, Belgium, 2007.

[10] Sahirman, S., Estimating Life-cycle Cost of West Virginia Fiber Reinforced Polymer (FRP) Bridge Decks, ISPA/SCEA Conference \& Training Workshop, 2010. 